\title{
Memory for how one learned of multiple deaths from AIDS: Repeated exposure and distinctiveness
}

\author{
DANEYAL MAHMOOD \\ New School University, New York, New York \\ DAVID MANIER \\ Lehman College, City University of New York, Bronx, New York \\ and \\ WILLIAM HIRST \\ New School University, New York, New York
}

\begin{abstract}
Studies of memories for the circumstances in which an emotional event was learned of have generally explored isolated, single-occurrence events_-for example, the Kennedy assassination. Such factors as the event's distinctiveness, its personal importance, its surprise, the elicited emotional change, and overt rehearsal have been posited as predictors of the memory's vividness and elaborateness. We examined whether these predictor variables would apply to a repeated trauma, using the repeated nature of the trauma to test, in particular, the contribution of distinctiveness. Focusing on the multiple deaths of loved ones from AIDS that many gay men have experienced, we contrasted the vividness and elaborateness of the circumstantial memory of the first death encountered with that of the most recent death, treating distinctiveness as the number of intervening deaths. In an analysis of responses by 80 gay men to a survey, no support was found for the claim that distinctiveness predicts a circumstantial memory's vividness or elaborateness. Only emotional change predicted these characteristics of the memories.
\end{abstract}

In the last 3 decades, many gay men and other victims of the AIDS epidemic have faced multiple deaths in a relatively short period of time, in some cases losing their entire social network to AIDS in a few years. Such repeated trauma undoubtedly has a range of psychological effects. In this article, we explore the psychological consequences of repeated trauma by examining the memories that individuals have of the circumstances under which they learned of the death of a friend, relative, or lover who suffered from AIDS. The study of memories for the circumstances in which an emotional event was learned of dates back to Brown and Kulik's (1977) study of the assassination of John F. Kennedy. Since then, a host of events have been studied: disasters, such as Hurricane Andrew, the explosion of the Challenger, or the attack of September 11; major political events, such as the beginning of the Gulf War or the resignation of Margaret Thatcher; and of course, the assassination of political figures, such as (in addition to John F. Kennedy) Malcolm X and Olaf Palme (Bohannon, 1988; Bohannon \& Symons, 1992; Brown \& Kulik, 1977;

Support from grants from the John S. McDonnell Foundation and from the NIMH (1-RO1-MH066972) is gratefully acknowledged. The authors thank Robert Meksin for his suggestions. Correspondence concerning this article should be addressed to W. Hirst, Department of Psychology, Graduate Faculty, New School University, 65 Fifth Avenue, New York, NY 10003 (e-mail: hirst@ newschool.edu).
Christianson, 1989; McCloskey, Wible, \& Cohen, 1988; Neisser \& Harsch, 1992).

Some researchers have emphasized that these events are not only emotionally charged, but also public, in that they are usually experienced not by an individual alone, but by a group of people, and often are talked about by an even larger group (Neisser, 1982). A death from AIDS is usually also public, although the public is often much smaller, often limited to friends, colleagues, and relatives of the deceased (see Christianson \& Loftus, 1990, Reisberg, Heuer, McLean, \& O'Shaughnessy, 1988, and Rubin \& Kozin, 1984, for studies of similar, smaller public events, i.e., death announcements more generally and reports of a pregnancy test). ${ }^{1}$ As these lists indicate, the literature has focused almost entirely on isolated, singleoccurrence emotional events, such as assassinations. Does what we know about memory for the circumstances in which an isolated, single-occurrence emotional event is learned of apply to repeated trauma?

As Brown and Kulik (1977) described them, memories of the circumstances in which an emotional event is learned of appear to differ substantially from normal memories, with the memories being more vivid, more elaborate, and putatively more accurate than normal memories. Indeed, Brown and Kulik found them so different from normal memories that they not only provided a distinct label for them—flashbulb memories — but also 
posited that they may involve a separate, special memory mechanism, which they described by the catch-phrase "Now Print!"

Brown and Kulik's (1977) study was retrospective and, hence, could not experimentally assess the accuracy of the memories they elicited. More recent work has collected recollections of emotional events shortly after they occurred versus after a substantial time interval. This literature has been fairly consistent in refuting Brown and Kulik's claim of extraordinary accuracy. For example, by contrasting memories of the circumstance of learning of the verdict of the O. J. Simpson trial shortly after the announcement was made with memories collected 32 months later, Schmolck, Buffalo, and Squire (2000) found that over $40 \%$ of the 32-month-old memories contained major distortions. Few psychologists now endorse the claim that special memory mechanisms are involved, positing instead that ordinarymemory mechanisms underlie the widely documented vividness and elaborateness of these memories (see Conway, 1995, for a review, as well as McCloskey et al., 1988, for a discussion of the distinction between special and ordinary memory mechanisms). Inasmuch as the term flashbulb memories appears to carry with it a commitment to the memories' accuracy and a special mechanism, we avoid the term in the present article and refer, instead, to circumstantial memories of emotional public events, or more briefly, circumstantial emotional memories.

The question here is not whether this work on accuracy can be extended to repeated emotional events. There is no reason to expect that repeated trauma would produce circumstantial memories any more or less accurate than the memories observed for isolated, single-occurrence emotional events. We focus here on two characteristics of circumstantial emotional memories that have been demonstrated in every study since Brown and Kulik (1977): the vividness of the imagery in the memory and the elaborateness with which the memory is remembered. Do vividness and elaborateness diminish as a trauma is repeated? One reason they might is that events become less distinctive as they are repeated. Many researchers have speculated that distinctiveness may be one of the factors accounting, at least in part, for the quality of circumstantial emotional memories (McCloskey et al., 1988; Neisser et al., 1996; Winograd \& Killinger, 1983). Although the positive contribution of distinctiveness to explicit memory can be traced back to von Restorff (1933; see Wallace, 1965, for the most recent review), in recent years, this contribution has been observed in tests of implicit memory as well (Geraci \& Rajaram, 2002). Moreover, distinctiveness can aid in the rejection of false memories (Dodson \& Schacter, 2002).

Distinctiveness effects can be observed in tests of memory when these are defined in categorical terms (Geraci \& Rajaram, 2002; Hunt \& Mitchell, 1982). For instance, according to Rubin, Rahhal, and Poon (1998), adolescents may remember their first romantic kiss because it is distinctive, but as romantic kissing becomes more common, they may find each kiss less memorable. So it could also be with death from AIDS. The first death from AIDS may be distinctive, but as one death follows another, this distinctiveness may fade.

It is difficult to determine whether distinctiveness is a factor in the vividness and elaborateness of a circumstantial emotional memory, in that all the events examined to date have been isolated, single occurrences. If distinctiveness is a factor, the vividness and elaborateness of circumstantial memories of repeated trauma should decline as the trauma loses its distinctiveness. On the other hand, circumstantial emotional memories may remain vivid even as the trauma is repeated, if distinctiveness does not make a critical contribution. If we operationally define distinctiveness in terms of the number of deaths of lovers, friends, or relatives from AIDS experienced by an individual, we can explore its contribution to circumstantial traumatic memory, examining whether, as the number of intervening deaths increases, the circumstantial memory of more recent deaths becomes less vivid and less elaborate than the circumstantial memory of the first death.

Of course, other factors may also contribute. Distinctiveness may not be a strong predictor of the vividness or elaborateness of a circumstantial emotional memory, and a memory of a death may remain vivid and elaborate no matter how many deaths preceded it. Under these circumstances, possible contributing factors might include (1) emotional change, (2) surprise, (3) overt rehearsal, and (4) personal importance and related variables, such as consequentiality, personal interest, and prior knowledge. Although these factors have all been proposed as predictors of the vividness and elaborateness of circumstantial memories (emotional change, Bohannon, 1988, Conway, 1995, Pillemer, 1984, and Reisberg et al., 1988; surprise, Finkenauer et al., 1998; overt rehearsal, McCloskey et al., 1988; personal importance and related variables, Brown \& Kulik, 1977, Conway, 1995, Rubin \& Kozin, 1984, and Schmolck, Buffalo, \& Squire, 2000), they may not figure strongly for repeated trauma. Consider emotional change. Death may lose its emotional character when one death follows another. When it comes to AIDS, this observation about death almost has become a matter of fact among some journalists and commentators, who have noted that, as the gay community has confronted the AIDS epidemic, it has become inured to death, numbed after repeated exposures to loss and grief (Folkman, 1993; Odets, 1995; Shilts, 1987). If this observation is validand there are no empirical data to support it-one would need to seek variables other than emotional change to account for vivid and elaborate circumstantial memories of repeated trauma.

Thus, in the present study, we investigated whether factors mentioned in the context of isolated, singleoccurrence events can predict the vividness and elaborateness of circumstantial memory for repeated trauma. Specifically, we explored whether circumstantial memories become less vivid and elaborate as the number of 
deaths from AIDS that an individual encounters increases. Although distinctiveness has been mentioned repeatedly in the literature as a predictor of the character of a circumstantial memory, it is unclear whether it will apply to something as emotionally salient as death, even if deaths follow one after the other. We also explored whether factors that have been discussed in the literature on circumstantial memory for isolated traumatic events will continue to play a role with repeated trauma-such factors as emotional change, personal importance, overt rehearsal, and surprise. Finally, we explored specific demographics of the gay population used in this study, to determine whether they would have a bearing on the quality of the circumstantial memory. For instance, would the HIV status of the recipient of the news and his relationship to the deceased influence the quality of the circumstantial memory? One would expect that recipients might treat the events as personally more important if they are HIV +, inasmuch as the announcement might underscore their own concerns about death. Moreover, one might expect a greater emotional change and a higher level of personal importance the closer the relationship of the deceased is to the recipient of the news, given that people are usually more affected by a death of a loved one or a close friend than of an acquaintance.

\section{METHOD}

\section{Participants}

The 80 participants were self-identified gay men who were solicited from gay organizations in New York City (the NYC sample) and gay-identified bulletin boards and chat rooms on the Internet (the Internet sample). The Internet sample was largely from regions outside the New York City area. The participants in the NYC sample were given a printed form of the questionnaire. The participants in the Internet sample were sent the questionnaire electronically and were asked to respond electronically. We ended our effort to find participants when, for each of the two samples, 40 questionnaires, 20 of Version A and 20 of Version B, had been returned. The response rate for the NYC sample was $31 \%$. For the Internet sample, we posted notices on bulletin boards and chat rooms and simply waited for responses. Our sample cannot be construed as representative of either the population overall or the gay population, a problem encountered by most research dealing with gay men (e.g., Bell $\&$ Weinberg, 1978). Given the nature of our solicitation, the respondents were probably fairly well integrated into the gay community. Such individuals have been linked to a higher incidence of loss and AIDS-related bereavement (Dean, Hall, \& Martin, 1988). Whereas such a link underscores the nonrepresentativeness of our sample, it also indicates that our sample should be composed of just those people we are seeking - those who have experienced many AIDS-related deaths.

\section{Measures and Scoring}

The participants were asked to respond to a series of questions for two events: learning about the first and the last deaths of someone close to them who had died from AIDS (see the Appendix). The questions were the same for both events. Half of the participants were asked initially to fill out the series of questions for the first death and then for the second (Version A); the order was reversed for the other half of the participants (Version B).

For each memory (first and recent), the questionnaire was divided into four sections. In the first section, the participants were asked to reveal their HIV status. They were given options of "negative," "positive," "don't know," and "rather not say." Five respondents indicated "don't know" and were scored as being HIV negative. No respondents answered "rather not say." In the first section, we also asked how many deaths of "lovers, close friends, or relatives due to AIDS" the respondent had experienced.

In the second section, we asked the respondent to describe, in as much detail as possible, what happened when they learned about the first (recent) death of a loved one from AIDS. This probe was open-ended and allowed the respondents to freely recall the event.

The third section consisted of a series of probes about circumstances. The participants were asked about (1) the location at which they had learned of the death, (2) ongoing events at the time, (3) the informant, (4) the emotional state of the informant, (5) their own affect, and (6) the aftermath. (Following Brown \& Kulik, 1977, we will refer to these as the canonical categories.)

The participants were also asked to identify the nature of the lost relationship, choosing between 1 for acquaintance, 2 for friend, 3 for close friend, 4 for relative, or 5 for lover. Because a relative is nonspecific in terms of degree of intimacy, if the participants had lost relatives they were instructed to further specify the closeness of the relationships. Unfortunately, half the participants who had lost a relative did not specify the nature of the relationship any further. Consequently, we simply treated the response they gave to the original query as definitive.

The last section obtained measures for four putative predictor variables: emotional change, personal importance, surprise, and overt rehearsal. The probe questions were based on Rubin and Kozin (1984). In addition, we asked the participants to indicate how old the memory was. Finally, we assessed vividness by asking the participants to respond to the question, "When you think about the time you heard the news about this death, to what extent do you reexperience the original visual scene (or the original sounds, touches, smells, etc.)?" with a value ranging from 1 (no image at all) to 7 (as vivid as normal vision).

To obtain a measure of elaboration, following other studies (e.g., Bohannon, 1988; Bohannon \& Symons, 1992; Brown \& Kulik, 1977; Christianson, 1989; McCloskey et al., 1988; Pillemer, 1984; Rubin \& Kozin, 1984), we derived a measure of elaborateness from the responses to the six canonical categories. A score of 1 was given to responses that answered the question, although not necessarily with particular specificity. For example, "at home," as well as "on the stair between our kitchen and living room," received a score of 1. A score of 0 was given to all other responses, such as "So long ago-I can't remember-maybe TV or reading" or to instances in which no response was made. The measure of elaborateness was the sum of the scores for the six canonical categories. To check the reliability of our coding, all questionnaires were double coded, and kappas were calculated, with results of .90 or better.

\section{RESULTS}

Given that our sample of gay men came from two sources, we first compared the responses of the two groups of participants - the NYC and the Internet samples. In a series of one-way analyses of variance, we contrasted the responses of the two groups to each question in Part III of the questionnaire. We did not find a main effect for group ( $p<.05$ was used for all the statistical tests). Consequently, the remaining analyses were conducted by treating the sample population as a single group of 80 participants. A summary of response means for all these variables is presented in Table 1. Relevant correlational data are found in Tables 2 and 3 . We were unable to analyze the free recall data of Section II of the questionnaire. ${ }^{2}$ 
Table 1

Ratings for Assessed Attributes of First and Recent Memories, as Well as Dates of Memories and Number of Deaths

\begin{tabular}{lccccccc}
\hline & \multicolumn{3}{c}{ First Memory } & & \multicolumn{3}{c}{ Recent Memory } \\
\cline { 2 - 3 } \multicolumn{1}{c}{ Attribute } & $M$ & $S D$ & $n$ & & $M$ & $S D$ & $n$ \\
\hline Surprise & 2.86 & 2.19 & 79 & & 3.30 & 2.10 & 72 \\
Vividness* & 3.72 & 2.00 & 80 & & 4.48 & 2.05 & 72 \\
Emotional change & 5.17 & 1.62 & 80 & & 4.72 & 2.01 & 72 \\
Importance* & 5.71 & 1.39 & 80 & & 5.15 & 1.85 & 72 \\
Relationship & 2.84 & 0.77 & 80 & & 2.70 & 0.92 & 72 \\
Rehearsal & 4.94 & 1.58 & 80 & & 4.54 & 1.84 & 72 \\
Elaboration & 5.01 & 1.42 & 80 & 5.41 & 1.44 & 72 \\
Date (years) & 8.47 & 4.16 & 80 & 2.63 & 3.35 & 72 \\
Deaths & 14.95 & 22.05 & 80 & & & \\
\hline
\end{tabular}

Note-Range equals 1-7, except for relationship (1-5), date (years), and number of deaths. $* p<.05$.

In what follows, we first calculated correlations between the main variables and then followed these up with stepwise regression, to determine which subset of variables constituted a good model. In the main, the multiple regression data were computed using forward regression with a statistical significance of .05 for entry. In forward selection, a variable is entered into the model only if it results in a change in $R^{2}$ that is significantly different from 0 at the $5 \%$ significance level. The variable with the largest $R^{2}$ is entered first. As each variable enters the model, it is partialed out from the variables that have not yet entered the model. In effect, then, forward regressions are computed on partial correlations, controlling for the variable(s) already selected.

Before examining the quality of the circumstantial memories we collected, we wanted to classify the reported memories, using the criteria and labels proposed by previous researchers. These researchers identified a memory as a flashbulb memory if an individual was able to answer "yes" to the probe "Do you recall the circumstances in which your first (or last) close friend, lover, or relative died from AIDS?" and could provide information for at least one canonical category (Brown \& Kulik, 1977; Conway, 1995; McCloskey et al., 1988; Pillemer, 1984). All the first memories reported by the 80 men met this criterion. A full $61 \%$ remembered information from all six canonical categories. The mean age of first memories reported was 8.47 years $(S D=4.16)$. As for the re- cent deaths, 6 respondents had experienced only one death, and 2 had experienced multiple deaths but said they could not recall who was the most recently deceased. These respondents did not figure in subsequent analyses for recent memories. The most recent memories of all 72 respondents also fulfilled our criterion: Of the first and recent memories combined, $76 \%$ contained information from all six canonical categories for recent memories. The mean age of recent memories was 2.63 years $(S D=$ 3.35). Thus, regardless of the extent of their encounters with death from AIDS, all the participants reported memories that met the criterion of flashbulb, using the standard (albeit rather weak) criterion of one canonical feature, and a full $76 \%$ met a much stricter criterion that insisted on the presence of all six canonical features.

The mean scores for the vividness of the imagery were $3.72(S D=2.00)$ for first memories and $4.48(S D=2.05)$ for recent memories. A paired-samples $t$ test of the two memories indicated a significant difference for rated vividness between the two memories $[t(71)=-2.45$, $p<.05]$. As to elaboration, in both memories, mean scores for elaboration were relatively high. On a scale of 1 to 6 , mean scores for elaboration were $5.01(S D=$ $1.42)$ for first memories and $5.41(S D=1.44)$ for recent memories. The trend for first memories to be less elaborate than recent memories was not significant $[t(71)=$ $1.35, p<.10]$. The forgetting suggested by this trend was better observed by examining the percentage of participants who provided an answer to all six of the canonical categories. For first memories, it was $61.3 \%$, and for recent memories, it was $92.7 \%$, a significant difference $[t(71)=-2.15, p<.05]$. In general, the reported memories were both vivid and elaborate. Although the elaboration scores were particularly high, they offered a range that allowed the discovery of both significant correlations and significant regression results. Interestingly, both vividness and elaboration were lower for the first memories than for the most recent memories, suggesting that circumstantial emotional memories may decay over time.

\section{Mnemonic Quality and Distinctiveness}

We are chiefly interested, in this article, in the effect that distinctiveness of the remembered event has on the

Table 2

Correlations Among Variables Within First Memories $(n=80)$

\begin{tabular}{lcccccccccc}
\hline First Memory Variable & 1 & 2 & 3 & 4 & 5 & 6 & 7 & 8 & 9 & 10 \\
\hline 1. Emotional change & - & $.56^{* *}$ & $.48^{* *}$ & $.51^{* *}$ & .15 & $.35^{* *}$ & .12 & .08 & .01 & .15 \\
2. Importance & - & $.45^{* *}$ & $.47^{* *}$ & .10 & $.36^{* *}$ & .00 & .03 & .17 & .18 \\
3. Vividness & & & - & $.45^{* *}$ & $.41^{* *}$ & $.27^{*}$ & .05 & -.16 & .08 & .06 \\
4. Rehearsal & & & & - & .09 & -.06 & -.04 & .12 & $.24^{*}$ & .00 \\
5. Elaboration & & & & & - & .04 & .07 & -.20 & -.01 & .00 \\
6. Relationship & & & & & - & $.32^{*}$ & .07 & .04 & $.35^{*}$ \\
7. Surprise & & & & & & - & $.31^{*}$ & $.35^{* *}$ & .08 \\
8. Date of memory & & & & & & & - & $.35^{* *}$ & .07 \\
9. Number of deaths & & & & & & & & - & -.01 \\
10. HIV status & & & & & & & & & - \\
\hline
\end{tabular}

$* p<.05 . \quad * * p<.001$. 
Table 3

Correlations Among Variables Within Recent Memories $(n=72)$

\begin{tabular}{|c|c|c|c|c|c|c|c|c|c|c|}
\hline First Memory Variable & 1 & 2 & 3 & 4 & 5 & 6 & 7 & 8 & 9 & 10 \\
\hline 1. Emotional change & - & $.73 * *$ & $.74 * *$ & $.65 * *$ & $.48 * *$ & .18 & .09 & $-.10 *$ & .12 & -.17 \\
\hline 2. Importance & & - & $.51 * *$ & $.58 * *$ & $.24^{*}$ & .30 & -.06 & -.06 & .11 & .04 \\
\hline 3. Vividness & & & - & $.60 * *$ & $.48 * *$ & .15 & .10 & -.09 & .08 & -.17 \\
\hline 4. Rehearsal & & & & - & $.65^{*}$ & -.08 & -.05 & .00 & .10 & .00 \\
\hline 5. Elaboration & & & & & - & .07 & .27 & $-.36 *$ & -.03 & -.19 \\
\hline 6. Relationship & & & & & & - & .13 & .05 & .12 & -.02 \\
\hline 7. Surprise & & & & & & & - & -.10 & -.06 & $-.27 *$ \\
\hline 8. Date of memory & & & & & & & & - & .20 & -.19 \\
\hline 9. Number of deaths & & & & & & & & & - & -.01 \\
\hline 10. HIV status & & & & & & & & & & - \\
\hline
\end{tabular}

$* p<.05 . \quad * * p<.001$.

quality of memory for this event, focusing on its vividness and elaborateness. As was noted in the introduction, we measured distinctiveness in terms of the number of deaths, asking in our questionnaire, "How many deaths of lovers, close friends, or relatives due to AIDS have you experienced?" Although 5 was the most frequent response, responses of 40,50, and 90, and one response of 159 deaths occurred. On average, the participants in our study had survived 14.95 deaths, with a mode of 5.0 $(S D=22.05)$. The large spread in responses most likely stems from the ambiguity of the word friend. Some participants may have included people that they knew slightly but were friendly with, or felt fondness toward, such as a co-worker. Given that a response of 159 is no less valid than a response of 5,20, or 50, all the data were factored into the final analysis.

The number of deaths experienced by the participants had only marginal effects on the rest of our data, and what effects we did find did not involve either vividness or elaboration. There were significant positive correlations between the number of deaths and the frequency with which the first memory was rehearsed $(r=.24, p<$ $.05)$, as well as the level of surprise associated with the first memory ( $r=.35, p<.001)$. We undertook multiple regression analyses, treating number of deaths as the independent variable. The number of deaths survived accounted for a significant proportion of the variation when surprise was the dependent variable $[F(1,77)=$ $\left.10.51, M S_{\mathrm{e}}=21.23, p<.01 ; R^{2}=.12\right]$. The number of deaths survived also accounted for significant proportions of the variation when the frequency with which the first memory was rehearsed served as the dependent variable $\left[F(1,78)=4.76, M S_{\mathrm{e}}=24.56, p<.05 ; R^{2}=.06\right]$.

Not surprisingly, there was a significant positive correlation between the date of the first death and the number of deaths that had occurred since that time. This raises the possibility that the effect of number of deaths on rehearsal and surprise may merely be a consequence of the passage of time, with more rehearsal and more surprise associated with older memories. When we partialed out length of time in our correlational analysis, we found that the few significant positive correlations observed between number of deaths and other variables disappeared.
Our main interest, however, is not in the influence that multiple deaths have on memories for the first death, but in the influence they have on memories of the most recent death. If there was an effect, we did not detect it. We failed to find any significant correlations between the number of deaths and any of our other variables when we examined the results for the most recent death. People were as likely to react emotionally, to have a vivid image of learning of the death, or to feel that the news was important if they had experienced only a few deaths or if they had experienced many deaths. If we use vividness and elaboration as a measure of the quality, multiple trauma had no effect on the quality of circumstantial memory of the trauma. Moreover, multiple encounters with death did not diminish the emotional change that occurred when people heard about a new death.

\section{Mnemonic Quality and Other Predictor Variables: Emotional Change, Personal Importance, Overt Rehearsal, and Surprise}

If the participants did indeed form vivid and elaborate memories, even with repeated trauma, were other predictor variables that are associated with vivid and elaborate memories of isolated, single-occurrence emotional events also associated with vivid and elaborate memories of repeated trauma? For first memories, vividness significantly correlated positively with emotional change $(r=.48, p<.001)$, importance $(r=.45, p<.001)$, rehearsal $(r=.45, p<.001)$, elaboration $(r=.41, p<.001)$, and relationship $(r=.27, p<.05)$. For recent memories, significant positive correlations were found for emotional change $(r=.74, p<.001)$, importance $(r=.51$, $p<.001)$, rehearsal $(r=.60, p<.001)$, and elaboration $(r=.48, p<.001)$. Two regression analyses were conducted to assess the relative contributions of relevant significantly correlated variables on vividness. For first memories, emotional change and importance accounted for a significant proportion of the variation in vividness $\left[F(2,77)=14.09, M S_{\mathrm{e}}=69.2, p<.0001 ; R^{2}=.22\right.$ for emotional change only, and $R^{2}=.28$ for emotional change with importance]. The remaining variables (relationship to the deceased and rehearsal) did not make significant contributions, explaining less than $1 \%$ of the variation in first memory's vividness. For the most re- 
cent memory, emotional change by itself accounted for a significant proportion of the variation in vividness $\left[F(1,69)=84.39, M S_{\mathrm{e}}=58.58, p<.0001 ; R^{2}=.55\right]$. The remaining variables (rehearsal and importance) did not make significant contributions, explaining less than $1 \%$ of the variation in recent memory's vividness.

As to elaboration, the correlations between elaboration and other variables differed for the two memories. For first memories, elaboration correlated significantly only with vividness $(r=.41, p<.001)$. For the most recent memory, elaboration correlated significantly with vividness $(r=.48, p<.001)$, emotional change ( $r=$ $.48, p<.001)$, importance $(r=.24, p<.01)$, rehearsal $(r=.65, p<.01)$, and the date of the memory $(r=$ $-.36, p<.01)$.

Two multiple regressions were used to assess the relative contributions of all significantly correlated variables. Results indicated that vividness accounted for a significant proportion of the variation in first-memory elaboration $\left[F(1,78)=15.85, M S_{\mathrm{e}}=15.89, p<.001\right.$; $\left.R^{2}=.17\right]$. With emotional change, importance, vividness, rehearsal, and the date of the memory as predictor variables, emotional change and the date of the memory accounted for significant proportions of the variation in recent-memory elaboration $\left[F(2,68)=18.39, M S_{\mathrm{e}}=\right.$ $16.84, p<.0001 ; R^{2}=.23$ for emotional change only, and $R^{2}=.35$ for emotional change with the date of the memory]. The remaining variables (vividness, importance, and rehearsal) were not statistically significant, each contributing less than $1 \%$ to the variation in recentmemory elaboration.

These findings for vividness and elaboration are consistent with almost all models of formation and retrieval of circumstantial traumatic memories in treating emotional change as a critical variable. As for the contribution that vividness makes to elaboration, it is commonsensical: People are more able to remember details about the context in which they heard about a death if they have a vivid image of the setting. The contribution that the date of the recent memory makes to elaboration may merely reflect the fact, as we have seen, that circumstantial traumatic memories decay with the passage of time, albeit perhaps more slowly than many other types of memories.

The results for overt rehearsal deserve comment. Whereas we found a positive correlation between rehearsal and both vividness and elaboration for recent memories, we did not find that the number of rehearsals predicted either vividness or elaboration in the regression analysis. As a check on this finding, we divided the estimates of rehearsal into two equal groups and then tested, with a $t$ test, whether average vividness and elaborateness ratings of the high-rehearsal group (vividness, 4.13; elaboration, 5.31) were greater than those of the low-rehearsal group (vividness, 4.03; elaboration, 5.09). Although one can observe a numerical difference, it was not significant $[t(70)=1.27, p=.10]$.

The significant positive correlations may have arisen because vivid and elaborate memories are overtly re- hearsed more often, not because overt rehearsal leads to more vivid and elaborate memories. Consider first memories. In a multiple regression analysis that treated emotional change, importance, and vividness of first memories as predictors of reported number of rehearsals, emotional change and importance accounted for a significant proportion of the variation in first-memory rehearsals $\left[F(2,77)=17.64, M S_{\mathrm{e}}=37.77, p<.0001\right] . R^{2}$ equaled .26 for emotional change only and .31 for emotional change with importance. The remaining variable (vividness) did not make a significant contribution, explaining less than $1 \%$ of the variation in first-memory rehearsals. This pattern probably arose because the importance and the emotional character of the first event led people to talk about the event more often.

For recent memories, with elaboration added to the equation, only emotional change accounted for a significant proportion of the variation in rehearsal $[F(1,69)=$ $\left.49.82, M S_{\mathrm{e}}=25.49, p<.0001\right] . R^{2}$ equaled .42 . Vividness, importance, and elaboration did not make significant contributions, each explaining less than $1 \%$ of the variation in recent-memory rehearsals. As with first memories, people may have talked more about the recent event if it was emotionally charged.

We need to approach our data on overt rehearsal cautiously, inasmuch as our participants did not report rehearsing the events frequently. On our scale of 1 to 7 , where 1 represents never and 7 represents more than 30 times, mean scores for rehearsal were $4.94(S D=1.58)$ for first memories and $4.54(S D=1.84)$ for recent memories. These figures correspond to somewhere between four and seven rehearsals per memory on average. It is unclear what to make of these relatively low numbers, although it should be kept in mind that the figure refers to the number of times someone thought about hearing the news of the death, not about the deceased himself or other events involving the deceased, including his illness. A paired-samples $t$ test comparing first memories with recent memories failed to show a significant difference for rehearsal.

To make one final comment, in this analysis so far, we have treated importance and emotional change as separate variables. They clearly mean different things, and we probed them with different questions. Nevertheless, one might expect that they will be highly correlated: An important announcement about a death is likely to elicit emotional change, and a death announcement that elicits emotional change is likely to be viewed as important. In our survey, mean scores for importance were moderately high for both memories. On a scale of 1 to 7 , where 7 represents tremendous importance to you at the time and 1 represents no importance to you at the time, mean scores for importance were $5.71(S D=1.39)$ for first memories and $5.13(S D=1.85)$ for recent memories. A paired-samples $t$ test indicated that this difference between first and recent memories was statistically significant $[t(69)=2.34, p<.05]$. Turning now to the correlations between importance and emotional change, as Tables 2 and 3 indicate, they were significantly corre- 
lated for both first and recent memories. Interestingly, the pattern of correlations for importance in first and recent memories was similar to the pattern of correlations for emotional change, suggesting that they may have been tapping into related aspects of circumstantial memories.

\section{Mnemonic Quality and Participant \\ Characteristics: HIV Status and \\ Relationship to the Deceased}

HIV status. We predicted that the memories of participants who were seropositive should be more vivid and elaborate than those who were seronegative, because the former should find the death of a lover, friend, or relative from AIDS to be more personally important than did those who were seronegative. The results did not support this conjecture. Of the 80 participants, 61 participants reported being HIV negative, and 19 reported being HIV positive. Not surprisingly, we found a significant positive correlation between the participants' serostatus and their relationship to the deceased in their first memory $(r=.35, p<.01)$.

With serostatus as a predictor variable, a multiple regression analysis showed that HIV status accounted for a small but significant proportion of the variation in the participants' relationship to the deceased in the firstmemory condition $\left[F(1,78)=10.80, M S_{\mathrm{e}}=14.52, p<\right.$ $\left..01 ; R^{2}=.12\right]$. Many of those who died may have been lovers of the respondents reporting positive HIV status. Unexpectedly, for recent memories, we found a significant negative correlation between having a positive serostatus and surprise $(r=-0.27, p<.01)$. Again, with serostatus as a predictor variable, a multiple regression analysis showed that HIV status accounted for a significant proportion of the variation in the participants' surprise at the recent death $[F(1,69)=5.26$, $\left.M S_{\mathrm{e}}=18.24, p<.05 ; R^{2}=.07\right]$. Overall, however, the effect of HIV status had little consequence on how people remembered either the first death from AIDS they had encountered or the most recent death. This is not to say that people's present attitude does not influence how the past is remembered but only that HIV status does not seem to influence memory for the death of lovers, friends, or relatives from AIDS. People's attitudes about death and AIDS may be strong enough to overshadow most effects that HIV status may have on memory.

Relationship to the deceased. We also expected that the relationship to the deceased might affect the quality and character of the circumstantial memory. The pattern of correlations for the relationship to the deceased variable was as expected for the first memory. It correlated positively with the participants' ratings of surprise at learning of the first death $(r=.32, p<.005)$, as well as emotional change $(r=.35, p<.001)$, vividness $(r=$ $.27, p<.001)$, and the reported importance of the event $(r=.36, p<.001)$. A series of multiple regressions were used to assess the relative contribution of the participants' relationship to the deceased on each of these variables. In all cases, the equation was significant, with $R^{2}$ approximating .10 in each case [for surprise, $F(1,77)=$ $8.66, M S_{\mathrm{e}}=14.37, p<.05 ; R^{2}=.10$; for emotional change, $F(1,78)=10.96, M S_{\mathrm{e}}=12.26, p<.01 ; R^{2}=$ .12 ; for vividness, $F(1,78)=6.13, M S_{\mathrm{e}}=11.28, p<$ $.05 ; R^{2}=.07$; for the importance of the event $[F(1,78)=$ $\left.11.46, M S_{\mathrm{e}}=21.57, p<.01 ; R^{2}=.13\right]$. Thus, a respondent's relationship to the deceased influenced the quality of the circumstantial memory, at least as measured by the participant's rating of vividness. It also affected how surprised and emotionally changed the respondent was and how important he thought the news was.

These findings are consistent with the traditional expectation about emotional events, in that more intimate loss should register a greater degree of surprise, personal importance, and emotional change. It is also not surprising that participants who report more significant loss for first memories reported less emotional change at the discovery of more recent loss $(r=-.25, p<.05)$. Thus, although the number of deaths may not have mattered, the nature of the initial loss did.

The relationship to the deceased in the most recent memory showed no significant influence on any variable. Lost here are the significant positive correlations with emotional change, surprise, vividness, and importance, which were found for first memories.

This pattern of results is not due to any difference in distribution of the participants' relationship to the deceased for first and last memories (see Table 4). It may, however, merely be a consequence of how we measured emotional change. In the short term, the news of any friend's death may be quite stirring, regardless of the level of closeness. As a result, for recent deaths, the participants may have rated strong emotional change, surprise, and so on, regardless of the intimacy of the relationship. This is not to say that the participants could not differentiate between, for example, the emotional change they felt when hearing of a lover's death versus a friend's death. But we did not ask the respondents to compare the level of emotional change across instances, but only to assign a rating as to the extent of emotional change of a particular death. With the passage of time, however, the emotional change may have diminished, and ceiling effects may have disappeared. The participants may now have been inclined to supply a lower rating to the emo-

Table 4

Distribution of Participant's Relationship to the Deceased for First and Recent Memories

\begin{tabular}{lccccc}
\hline & \multicolumn{2}{c}{ First Memory $(n=80)$} & & Recent Memory $(n=72)$ \\
\cline { 2 - 3 } \multicolumn{1}{c}{ Variable } & Frequency & Percent & & Frequency & Percent \\
\hline Acquaintance & 2 & 3 & & 5 & 7 \\
Friend & 22 & 28 & & 25 & 35 \\
Close friend & 46 & 58 & & 30 & 42 \\
Lover & 7 & 9 & & 8 & 11 \\
Relative & 3 & 4 & & 3 & 4 \\
\hline
\end{tabular}


tional change that they felt on learning of the death of a friend than that felt on learning of the death of a lover.

\section{GENERAL DISCUSSION}

Does multiple trauma affect memories of the circumstances under which one learns about the trauma? Do these circumstantial memories for repeated trauma in the gay community support the claim of some commentators that the gay community has become numb with repeated exposures to death? Is distinctiveness a predictor of the quality of circumstantial emotional memories, as some researchers have suggested? The answer appears to be no to each of these questions. We could discern no effect of multiple deaths on the circumstantial memories associated with these deaths. Nor could we detect any influence on ratings of emotional change or importance of this recent death announcement. Of course, one may not be able to reduce as complex a notion as numbness to simple ratings of emotional change or importance, making any conclusion about the claim for numbness in the gay community tentative. As to our concerns about the character of the circumstantial memory, here it does seem legitimate to focus on vividness and elaborateness, inasmuch as Brown and Kulik (1977) have argued that these qualities (among others) characterize the difference between circumstantial emotional memories and ordinary memories.

Although the present study was not designed to test the accuracy of circumstantial traumatic memories, our results suggest that such memories do fade with time. In our study, first memories were significantly less vivid than recent memories, and there was a trend toward first memories being less elaborate than recent memories. These results support the more general claim that circumstantial emotional memories may be subject to decay, just as ordinary memories are. The present study, however, has not tried to compare the rate of decay of circumstantial emotional memories with that of other memories. Circumstantial emotional memories may decay over time, but they may decay at a slower rate than other memories.

As far as predictor variables go, as was noted in many cases, our most significant results rest on instances in which we failed to find an effect of a particular predictor variable. These negative findings are interesting because they were unexpected. Distinctiveness does not appear to play a decisive role, even though it no doubt has an effect on ordinary memories (for a review, see Wallace, 1965). Rehearsal also has an effect on ordinary memory, but the pattern we found was not straightforward: A memory's vividness or elaborateness could not be predicted solely on the basis of how much it was rehearsed. One had to factor emotional change into the equation.

If one compares the present results against those in other studies of circumstantial emotional memory, differences emerge. Consider our results and those of two well-conducted studies-one by Conway et al. (1994) and another by Finkenauer et al. (1998) — that used quite similar methodologies. The results of Conway et al. were similar to those found here. The elaborateness of the memory was a function of importance/consequentiality and emotional feeling state. Neither surprise nor overt rehearsal was a necessary factor in predicting elaborateness. On the other hand, according to Finkenauer et al., surprise can directly influence elaborateness or indirectly do so by affecting the emotional feeling state. Emotional feeling states do not directly influence elaborateness but can affect it indirectly, by increasing overt rehearsal. These differences may arise because the events themselves differed. For instance, in the case of the present study and that of Conway et al., who studied the resignation of Margaret Thatcher, the studied events had long-lasting consequences, were probably discussed extensively for months, and were anticipated to differing degrees. On the other hand, Finkenauer et al. examined an event-the sudden death of King Baudouin - that was quite surprising, and although no doubt sad for Belgians, it may not have had the same kind of long-lasting consequences or the level of long-term coverage or discussion as the deaths studied here or the event studied by Conway et al.

What is consistent in all the studies is the critical contribution of emotional change. It figured in every instance. If emotional change plays such a central role, one can ask whether it is legitimate to claim that the special qualities of circumstantial emotional memory are merely a consequence of ordinary memory mechanisms. At least two concerns arise. First, the present results indicated that it is not enough to extrapolate from what we know about memory for neutral or ordinary events to circumstantial memories for emotional events. The present finding concerning distinctiveness is a good example of the caution that must be exercised. Even though what we know about ordinary mechanisms of memory has led some researchers to predict that distinctiveness has a role in producing the quality of circumstantial emotional memory, we could not detect any contribution. A simple appeal to ordinary mechanisms may not be enough. One must carefully test for what mechanisms are involved.

Second, circumstantial emotional memory, or emotional memory more generally, may indeed involve special mechanisms. Not only are emotionally charged memories remembered better than neutral memories (Christianson, 1992), they also are mediated by the amygdala to an extent that memory for neutral events is not (LeDoux, 2002). Although the amgydala probably does not engage the "Now Print!" process discussed by Brown and Kulik (1977), it may nevertheless deserve the label of special in that it seems to specialize in memories for emotion. It is more important, however, to specify empirically the mechanisms underlying the distinctive character of circumstantial emotional memories than to decide whether these mechanisms should be labeled special or ordinary.

One final caveat: Although multiple encounters with death may not have influenced either the incidence of 
circumstantial memories or their character, we cannot assume from our results that distinctiveness is never a factor in the quality of circumstantial emotional memories or that multiple trauma never has an effect. The death of a friend or a lover may always elicit a strong emotion, no matter how frequently it occurs. But other incidents may lose their emotive saliency as they lose their distinctiveness. The attack on the World Trade Center elicited strong emotions, and many circumstantial memories were no doubt formed. However, if New York had been under constant attack and many skyscrapers had been routinely bombed, people may not have reacted as strongly as they did on September 11th, nor would they necessarily have formed a vivid and elaborate circumstantial memory. The study of circumstantial traumatic memories in war has not been done. Under such circumstances, distinctiveness may indeed be a factor. One can conclude from the present study only that distinctiveness does not contribute to the vividness and elaborateness of memories of the circumstances in which one learned of a death of a lover, a close friend, or a relative.

\section{REFERENCES}

Bell, A. P., \& Weinberg, M. S. (1978). Homosexualities: A study of human diversity. New York: Simon \& Schuster.

BohanNON, J. N., III (1988). Flashbulb memories for the space shuttle disaster: A tale of two theories. Cognition, 29, 179-196.

BohanNon, J. N., III, \& SYMONS, V. L. (1992). Flashbulb memories: Confidence, consistency, and quantity. In E. Winograd \& U. Neisser (Eds.), Affect and accuracy in recall (pp. 65-90). Cambridge: Cambridge University Press.

Brown, R., \& KULIK, J. (1977). Flashbulb memories. Cognition, 5, $73-$ 79.

Christianson, S.-Å. (1989). Flashbulb memories: Special, but not so special. Memory \& Cognition, 17, 435-443.

Christianson, S.-Å. (1992). Do flashbulb memories differ from other types of emotional memories? In E. Winograd \& U. Neisser (Eds.), Affect and accuracy in recall (pp. 191-211). Cambridge: Cambridge University Press.

Christianson, S.-Å., \& Loftus, E. F. (1990). Some characteristics of people's traumatic memories. Bulletin of the Psychonomic Society, 28, 195-198.

CONWAY, M. A. (1995). Flashbulb memories. Hillsdale, NJ: Erlbaum.

Conway, M. A., Anderson, S. J., Larsen, S. F., Donnelly, C. M., McDaniel, M. A., McClelland,A. G. R., Rawles, R. E., \& Logie, R. H. (1994). The formation of flashbulb memories. Memory \& Cognition, 22, 326-343.

DeAn, L., Hall, W. E., \& MARTin, J. (1988). Chronic and intermittent AIDS: Related bereavement in a panel of homosexual men in New York City. Journal of Palliative Care, 4, 54-57.

Dodson, C. S., \& SCHACTER, D. L. (2002). When false recognition meets metacognition: The distinctiveness heuristic. Journal of Memory \& Language, 46, 782-803.

Finkenauer, C., Luminet, O., Gisle, L., El-Ahmadi, A., van Der Linden, M., \& Philippot, P. (1998). Flashbulb memories and the underlying mechanisms of their formation: Toward an emotionalintegrative model. Memory \& Cognition, 26, 516-531.

FolKMAN, S. (1993). Psychosocial effects of HIV infection. In L. Gold- berger \& S. Breznitz (Eds. and Trans.), Handbook of stress (pp. 658681). New York: Free Press.

GERACI,L., \& RAJARAM, S. (2002). The orthographic distinctiveness effect on direct and indirect tests of memory: Delineating the awareness and processing requirements. Journal of Memory \& Language, 47, 273-291.

Hunt, R. R., \& Mitchell, D. B. (1982). Independent effects of semantic and nonsemantic distinctiveness. Journal of Experimental Psychology: Learning, Memory, \& Cognition, 8, 81-87.

LeDoux, J. E. (2002). Synaptic self: How our brains become who we are. New York: Viking.

McCloskey, M., Wible, C. G., \& Cohen, N. J. (1988). Is there a special flashbulb-memory mechanism? Journal of Experimental Psychology: General, 117, 171-181.

NeISSER, U. (1982). Snapshots or benchmarks? In U. Neisser (Ed.), Memory observed: Remembering in natural contexts (pp. 43-48). San Francisco: Freeman.

NeISSER, U., \& HARSCH, N. (1992). Phantom flashbulbs: False recollections of hearing the news about Challenger. In E. Winograd \& U. Neisser (Eds.), Affect and accuracy in recall (pp. 9-31). Cambridge: Cambridge University Press.

Neisser, U., Winograd, E., Bergman, E. T., Schreiber, C. A., PAlmer, S. E., \& Weldon, M. S. (1996). Remembering the earthquake: Direct experience vs. hearing the news. Memory, 4, 337-357.

ODETS, W. (1995). In the shadow of the epidemic: Being HIV-negative in the age of AIDS. Durham, NC: Duke University Press.

Pillemer, D. B. (1984). Flashbulb memories of the assassination attempt on President Reagan. Cognition, 16, 63-80.

Reisberg, D., Heuer, F., Mclean, J., \& O'Shaughnessy, M. (1988). The quantity, not the quality, of affect predicts memory vividness. Bulletin of the Psychonomic Society, 26, 100-103.

RoSALDO, R. (1993). Culture and truth: The remaking of social analysis. Boston: Beacon.

Rubin, D. C., \& KozIn, M. (1984). Vivid memories. Cognition, 16, 81-95. Rubin, D. C., Rahhal, T. A., \& PoOn, L. W. (1998). Things learned in early adulthood are remembered best. Memory \& Cognition, 26, 3-19.

Schmolck, H., Buffalo, E. A., \& Squire, L. R. (2000). Memory distortions develop over time: Recollections of the O. J. Simpson trial verdict after 15 and 32 months. Psychological Science, 11, 39-45.

ShILTS, R. (1987). And the band played on. New York: St. Martin's. VON RESTORFF, H. (1933). Über die Wirkung von Bereichsbildungen im Spurenfeld. Psychologische Forschung, 18, 299-342.

WALLACE, W. P. (1965). Review of the historical, empirical, and theoretical status of the von Restorff phenomenon. Psychological Bulletin, 63, 410-424.

WinOGRAD, E., \& KiLlinger, W. A., JR. (1983). Relating age at encoding in early childhood to adult recall: Development of flashbulb memories. Journal of Experimental Psychology: General, 112, 413-422.

\section{NOTES}

1. Almost by definition, the events studied by Brown and Kulik (1977) and others are public in nature, in that they are discussed among members of a group. Death and birth are also events almost inevitably shared with others. Indeed, most, if not all, societies have public rituals marking such events (Rosaldo, 1993). Of course, some emotional events may be quite private in nature. Sexual abuse, for instance, may remain a secret between the perpetrator and the victim. Here, the size of the public is so small as to make the term public rather meaningless. To date, there has been little discussion about how private emotional events, such as some acts of sexual abuse, may differ mnemonically from more public emotional events, such as death or a natural disaster.

2. The free recall protocols were lost in the destruction of the World Trade Center. 


\section{APPENDIX}

Questionnaire

I.

1. If you know your HIV status and are inclined to reveal it, please do.
1. positive
2. negative
3. don't know
4. rather not say

2. How many deaths of lovers, close friends, or relatives due to AIDS have you experienced? (If uncertain, please approximate using a single figure, i.e., 2 or 5 , but not " $2-5$ ").

II.

Do you recall the circumstances in which you learned that your first (or last) close friend, lover, or relative died from AIDS? Please include whatever information comes to mind regardless of how irrelevant you think it may be.

III.

In answering the following questions, please be as specific as you can. If you can't remember the answer to any or several questions, leave them blank. What matters is that you put down only what you remember.

1. Who was the person who died from AIDS in relation to you? -circle one-
A. acquaintance
B. friend
C. close friend
D. lover
E. relative

(If person was a relative, please answer according to the closeness of the relationshipas well, i.e., very close, circle $\mathrm{E}$ and $\mathrm{D}$; close, circle $\mathrm{E}$ and $\mathrm{C}$; and so on).

2. Where were you when you first discovered the news of this death?

3. What were you doing when you first discovered the news of this death?

4. Who was the person(s) who informed you of this death?

5. What was the emotional state of the person(s) who told you of this death?

6. What was your emotional response upon hearing of the news this death?

7. What did you do immediately after hearing the news of this death?

IV.

Please answer the following using a 1 to 7 scale where indicated. 1

1. How personally important was this death? (1 means no importance to you at the time and 7 means tremendous importance to you at the time.)

2. When you think about the time you heard the news of this death, to what extent do you re-experience the original visual scene (or the original sounds, touches, smells, etc.)? (1 means no image at all and 7 means as vivid as normal vision.)

3. Did this death cause an emotional change in you? ( 1 means no, you felt exactly the same afterward, and 7 means as large an emotional change as ever occurs from one event to another.)

4. How surprised were you that this death occurred? (1 means not at all surprised,i.e., "figured it would happen," and 7 means as surprised as you have ever been about anything.)

5. How may times have you discussed this death since it occurred? ( 1 means no times, 2 means 1 time, 3 means 2-3 times, 4 means 4-7 times, 5 means 8-15 times, 6 means 16-30 times, 7 means more than 30 times.)

6. Please tell me as accurately as you can how long ago you learned of this death, for example, 5 hours (ago), 28 months (ago) or 15 years (ago).

\section{APPENDIX NOTE}

1. Not indicated for Question 6. 